NASA Technical Memorandum 83709

AIAA-84-1383

\title{
An Advanced Pitch Change Mechanism Incorporating a Hybrid Traction Drive
}

Bruce M. Steinetz

Lewis Research Center

Cleveland, Ohio

Donald F. Sargisson

General Electric Company

Evendale, Ohio

Graham White

Transmission Research Incorporated

Cleveland, Ohio

Stuart H. Loewenthal

Lewis Research Center

Cleveland, Ohio

Prepared for the

Twentieth Joint Propulsion Conference cosponsored by the AIAA, SAE, and ASME

Cincinnati, Ohio June 11-13, 1984

\section{NRSA}


Bruce M. Steinetz

Lewis Research Center

Cleveland, Ohio 44135

Donald F. Sargisson

General Electric Company

Evendale, Ohio $\mathbf{4 5 2 1 5}$

Graham White

Transmission Research Incorporated

Cleveland, Ohio 44106

Stuart H. Loewenthal

Lewis Research Center

Cleveland, Ohio 44135

Abstract

A design of a propeller pitch control mechanism is described that meets the demanding requirements of a high-power, advanced turboprop. In this application, blade twisting moment torque can be comparable to that of the main reduction gearbox output: precise pitch control, reliability and compactness are all at a premium. A key element in the design is a compact, high-ratio hybrid traction drive which offers low torque ripple and high torsional stiffness. The traction drive couples a high speed electric motor/alternator unit to a ball screw that actuates the blade control links. The technical merits of this arrangement and the performance characteristics of the traction drive are discussed. Comparisons are made to the more conventional pitch control mechanisms.

\section{Introduction}

Although propeller driven aircraft have flown successfully for over 70 years, 1 the exceptionally large blade torques and synchrophasing requirements of advanced turboprop (ATP) pitch change mechanisms have created new engineering challenges. An overall objective targeted by NASA is to design a modern turboprop that will cruise at a Mach number between 0.7 and 0.8 , achieve fue 1 burn and direct operating cost reduction on the order of 21 and 10 percent respectively, without a compromise in noise or engine emissions. This has caused the aircraft propulsion industry to take a hard look at both ol:d and new technologies to synthesize an optimum propulsion system.

One of the key technology areas identified is the development of a reliable, large size gearbox / pitch control mechanism (PCM) system. Although devices for achieving variable propeller pitch on earlier aircraft have demonstrated commercial acceptability, the torque required to effect the pitch change function has unfortunately multiplied dramatically. This large increase in pitch change torque, which is now almost as large as the propulsive torque has reopened the field of conventional PCM's to another round of technical scrutiny.

Two modern examples of a PCM are the two systems developed for a variable pitch fan under the NASA/General Electric Quiet Clean Short-Haul Experimental Engine Program (QCSEE ${ }^{2}, 3$ ). A schematic of one of the mechanisms appears in Fig. 1. Although both the QCSEE engine and ATP engine produce about $13000 \mathrm{hp}$, a total of $51000 \mathrm{in}$. lb is used to position the OCSEE 18-bladed variable pitch fan while nearly 490000 in. $1 \mathrm{~b}$. of blade torque is imposed on the ATP's 10 bladed variable pitch propfan (Fig. 2, ref. 4).

The PCM concept described in this study exhibits radical departures from previous historic practice. World War II propeller systems were either hydro-mechanical or electro-mechanical in nature. The changeover from piston engines to turbine engines did not cause the development of the PCM to change course markedly, although it did cause a significant increase in complexity for safety reasons. Piston engines in the 2000 to 3000 hp category were commonplace and the power level of earlier turboprop engines such as the Rolls-Royce "Dart", Bristol "Proteus" and the Allison T56 did not much exceed the power levels of the piston engines such as the Pratt Whitney R-2800 and 4360 and the Curtiss-Wright $3350 \mathrm{family.} \mathrm{Increase}$ in complexity for safety reasons mostly concerned itself with the safe operation of the airplane after fundamental single failures that could be perceived for either the turboprop engine or the propeller system.

Automatic drag limiting via auto-feather (coarsening of propeller blade angle), improved negative torque sensing systems and improved overspeed protection methods at all flight conditions were introduced in a timely manner. For some engines, such as the T56 model, auto-disconnect was also introduced as a gearbox sub-function to ensure that the propeller could not back-drive to the single-shaft gas generator with the attendant airplane drag increase that this implies.

The principal objective of this paper is to present a reliable electro-mechanical PCM concept that is markedly different from its early counterpart capable of meeting the requirements for an ATP propeller control system as out ined in Table I. The concept incorporates an autonomous, all-digital electronic control system using fiber-optic signalling together with an electrically commutated pitch control motor. The motor positions the propeller blades through a link mechanism driven by a hybrid traction drive/ball screw arrangement.

\section{PCM Description}

In selecting components for an advanced PCM, certain design features were identified as being clearly desirable. These features included: 
(1) An autonomous power source.

(2) Redundancy of control system inputs.

(3) An autonomous digital electronic control system.

(4) A modular design for ease in component removal.

(5) A completely separate motive power source for emergency feather.

(6) A travelling mechanical pitch lock.

(7) Highly precise pitch selection.

(8) Mechanical component hysteresis held to a minimum.

Autonomous power source. - Propeller PCM's that are hydraulically operated normally have required that hydraulic power be transported from the stationary housing to the rotating blade link mechanism through a hydraulic transfer bearing. Some later Hamilton Standard hydraulic propellers have used an assembly sandwiched between the rotating propeller and the gearbox forward face. In this arrangement there is no need for hydraulic slip rings as the entire pump and control assembly can be designed to be co-rotating with the propeller.

Previous electric propellers have been powered by current drawn from the main aircraft electrical system and transported across the stationary-torotating boundary by means of brushpacks and copper faced slip rings. In these designs the PCM motor is co-rotating with the propeller while the control unit and power source are located on the stationary side of the boundary.

All three of these concepts include undesirable features from the standpoint of reliability and maintenance. Hydraulic transfer bearings leak while electrical slip rings wear and cause electrical noise. The sandwich hydraulic system causes a larger propeller overhang moment and complicates rout ine maintenance.

An autonomous power system that eliminates the need for any form of slip ring becomes an attractive proposition. The advanced PCM design presented in this paper incorporates this feature.

Arrangement. - A schematic of an electromechanical PCM which meets all the requirements for an ATP propulsion system appears in Fig. 3. A high speed drive shaft extending from the main reduction gearbox (not shown, but discussed in ref. 5) is used to power an electric alternator that is mounted in and rotates with the propeller hub. Thus the transfer of power (nominally 20 to $30 \mathrm{hp}$ ) is through a rotating shaft that can be either speed additive or subtractive according to whether the drive shaft rotates in the opposite or same sense as the propeller. In either case a method has been created whereby no slip rings are required to transport electrical current since the alternator is already rotating with the propeller. The alternator's electric power is modulated by the self-contained rotating electronic control module before it is passed to the pitch control motor. Based on rotational speed commands or blade angle (beta) command signals passed across the rotating interface through a fiber optic slip ring, the high speed control motor adjusts blade position through a high reduction, low hysteresis drive system.

The drive mechanism consists of a $210: 1$ reduction ratio hybrid traction drive that couples the high speed motor to the ball screw. Connected to the ball screw nut are 10 fixed length blade links that accurately position each blade. Although aircraft quality, electric alternators with input speeds of $30000 \mathrm{rpm}$ and motors with output speeds of $40000 \mathrm{rpm}$ currently exist, a final tradeoff between electrical machinery speed and size must be made with respect to the size and complexity of the mechanical drive train. For purposes of this investigation, a nominal input speed of $20000 \mathrm{rpm}$ into the hybrid drive from the motor will be assumed. The expected physical size of the required electrical machinery is quite small; easily fitting into the bore diameter of the ball screw and weighing less than 25 lb for the alternator/ motor combination.

The drive mechanism is actuated only when a change in blade position is commanded and then mostly in a low speed, low power hunting mode so blade angle slew rates are generally less than $3 \% \mathrm{sec}$. The maximum motor speed is therefore rarely reached except for emergency feather or reverse pitch operation.

The PCM arrangement is modular by design and during maintenance each of the main drive components $c$ an be removed and replaced without disturbing the blade mounts. Individual components simply bolt together and do not require any complicated interconnecting lines found in most hydraulic systems. The component nature of the system also enhances health monitoring capability by allowing individual fault signals to be transmitted back to the cockpit across the fiber optic junction.

Emergency feather and pitch lock. - The proposed system is equipped with both emergency feather and pitch lock safety systems in the event of PCM systen malfunction. In the event of a PCM electrical system failure, an externally controlled, emergency fluid coupling connected to the hybrid drive's input shaft (not shown in Fig. 3) would fill and drive the blades to feather. Malfunction of the propeller pitch control, power supply or any mechanical component upstream of the ball screw will cause the travelling pitch lock mechanism to actuate.

The pitch lock mechanism consists of an electrically driven machine screw which causes the pitch lock stop to follow, with some small clearance, the main ball screw nut. One of the two parallel pitch lock screws is shown in Fig. 3 . The pitch lock stops typically lag the propeller blade angle by 1 to $2^{\circ}$. In the event of failure, the mechanical pitch lock arrests the natural tendency of the propeller to seek fine pitch which, if left unchecked, could lead to a potentially hazardous overspeed condition.

Blade angle control. - A significant departure from prior PCM systems is that only the control signal is passed across the rotating boundary between the spinner and stationary structure. The hydraulic or, as in this case, electrical "muscle" 
need not be passed through hydraulic transfer bearings or electrical slip rings.

There are several means of transmitting the control signal from the cockpit to the rotating spinner. Communicating the signal can be done electrically or hydraulically using slip rings or it can be done mechanically using cams and linkages. These conventional methods, however, can often be unreliable or difficult and costly to maintain. Crossing the rotating spinner boundary with electrical brushes, a rotating transformer a capacitor, or with radio waves are also possible approaches. In terms of interference, noise and reliability, one of the more attractive approaches is a fiber optic coupling. On the basis of bit error rate (a method of judging quality of signal transmission), studies 6 have shown that fiber optic links typically perform better than hard wire links. Besides these advantages, the proposed signal transfer module has high frequency and bandwidth capability and a potential for lower cost, size and weight. Accumulation of dirt can be prevented by means of engine purge air across the optical surfaces such as the arrangement shown in Fig. 4.

Precise pitch selection. - It is well understood that the propfan will require very accurate control and positioning mechanisms, as thrust response to change in blade angle is much more sensitive than conventional propellers. A representative blade twisting moment/blade angle schedule appears in Fig. 5. The main component of blade twisting moment is due to centrifugal forces. The aerodynamic portion accounts for only about 15 percent of total at cruise. The degree of precision required for synchrophasing mult iple engine propeller blade positions has not yet been fully established, but the system described here should be significantly more accurate than the current industry standard of about $\pm 5^{\circ}$ on blade clock position.

The three factors that contribute to this accuracy are the all-digital electronic control, low mechanical system hysteresis and high torsional stiffness. The envisioned all-digital electronic feedback control system can provide computation and positioning functions with greater accuracy than would be projected for conventional hydromechanical control and speed governing systems. Using appropriate sensors, required rate of pitch change and even acceleration/deceleration functions can be precisely calculated by the electronic controller.

The system described in this paper has a speed ratio of about $8000: 1$ (that is, a $20000 \mathrm{rpm}$ electric motor effecting a blade angle change rate of $15^{\circ} / \mathrm{sec}$ at maximum speed). If the total blade travel from full feather to full reverse is $105^{\circ}$ then the motor turns 22.2 revolutions for each degree of blade angle or $0.045^{\circ}$ of blade angular change for each revolution of the electric motor. A modern electronically commutated motor $c$ an be programmed to achieve any one of a precise number of selectable revolutions, and thus blade position resolution can theoretically be $0.05^{\circ}$ or less.

To achieve the potential blade position resolution requires that both mechanical hysteresis and torsional compliance be minimized. It is instructive to note that mechanical backlash that normally plagues servopositioning systems is of secondary importance here, since the centrifugal blade twisting moment is always present and always in the same direction, except for reverse pitch where blade positional accuracy is relative unimportant.

\section{Hybrid Drive, Ball Screw and Blade Links}

The mechanical portion of the PCM is essentially a high-ratio, speed reduction drive system that connects the control motor with the blade pitch position. The reduction ratio of $8000: 1$ in the mechanism is determined by the combination of maximum pitch change rate, in the present case $15^{\circ} / \mathrm{sec}$, and the maximum rated speed of the control motor. Superimposed on the pitch control members are the extreme pitch stops, emergency locks and emergency feather mechanism.

Although the control motor is capable of high speed rotation, this condition is experienced only at pre-flight checkout and at a demand for emergency reverse thrust. The PCM thus experiences in cruise flight intermittent forward and reverse cycles of low duration as the control motor seeks to keep the blades of one propeller at the same rotational speed and the same clock position as the blades on a master propeller and engine. The duty cycle on the pitch control system is therefore low from a rotational speed standpoint; but it is high in respect of working mainly at or near the maximum rated torque.

A low-weight design of PCM that is appropriate to the high torques of an ATP aircraft having minimum hysteres is and maximum stiffness is shown in Fig. 3. The ten blades are held at any required pitch by tension links that are connected at one end to blade pitch horns, and at the other end to a travelling nut. Axial motion of the nut, and hence the pitch of all ten blades, is controlled by rotation of the hollow ball screw. Blade centrifugal aerodynamic forces keep a constant-direction torque on the ball screw irrespective of its direction of rotation. Ball screw thrust is carried on a split inner-race bearing while a roller bearing positions the front end of the screw.

Ease of accessibility for maintenance results from the hybrid traction drive unit being near the front of the propeller hub, with the motorl alternator carried inside the ball screw. Both of these electrical units are oil cooled and can be removed without disturbing the propeller hub. Use of the hybrid traction drive enhances PCM stiffness. Analysis recently completed indicates that torsional stiffness for traction drive contacts can be from 2 to 5 times greater than comparable gear meshes that suffer from beam bending and $r i m$ deflection of the gear teeth. Although a slight penalty is paid with a ring gear output stage in the proposed arrangement, using stiff rollers at the input stage contributes to output drive stiffness by a ratio squared effect.

Hybrid drive assembly. - The hybrid (traction/ gear) drive achieves in one assembly the 210:1 speed ratio between the ball screw, at $95 \mathrm{rev} / \mathrm{min}$, and the drive motor at a nominal $20000 \mathrm{rev} / \mathrm{min}$ (Figs. 6 and 7 ). The sun roller is double-sided and of one-piece construction. Five sets of stepped first-row rollers surround the sun rollers and carry torque to stepped second-row rollers. 
In turn, the second-row rollers drive a third set of rollers. The only bearings used in the assembly are those that transmit the tangential loads from the third-row rollers into the carrier frame.

Enclosing the roller assembly is a pair of ring rollers whose function is to react the radial loads set up at the tractive contacts. The retaining rings are free-rolling and transmit no torque. Their axial separation, however, controls the preload level built into the traction drive. Adjustment of this preload and accommodation of roller diameter tolerances are controlled by the spacer between the ring rollers. A closer approach of the ring rollers, set by a narrow spacer, results in the rings riding on a slightly larger diameter of the outer-roller profiles. All tractive contacts in the assembly then experience an increased radial force or preload, which allows higher torque to be transmitted, while the retaining rings act as stiff springs as they tend to deform into a five-lobed section. The amount of preload is set to resist slip under peak overtorque conditions. An alternate arrangement would be to employ a cam actuated, automatic loading mechanism (similar to a ramp roller clutch), to adjust roller loading in proportion to transmitted torque as discussed in Ref. 8. However, in this application, fixed preload is probably acceptable, since torque loading, mainly due to centrifugal blade twisting movements, is essentially constant at cruise.

Five toothed pinions affixed to both ends of the outer row planet rollers engage the output ring gears. Double pinions and rings result in an axially-symmetric assembly, with the advantage that the outer-row rollers and their support bearings experience no skewing moments. With the present design it proves convenient to react torque from the geared rings to the propeller hub, leaving the roller carrier frame to drive the ball screw. In this case, planetary action resilts, but the accompanying boost in reduction ratio, to $210: 1$, is negligible in comparison with the 209:1 ratio which would be obtained with the carrier frame held by the hub. The complete hybrid drive assembly, rated at an output torque of $12840 \mathrm{in.lb}$. weighs approximately $32 \mathrm{lb}$.

Grease lubrication. - Traction drives, in common with geared drives, require a small amount of oil or grease for purposes of lubricating the highly loaded contacts. The low average level of power supplied by the pitch control motor results in correspondingly low losses in the traction unit. It is not necessary, therefore, for the lubricant to dissipate significant amounts of heat; the main function of the lubricant is to prevent wear and corrosion of the roller traction surfaces.

The use of traction grease has the major advantage that no pump or filter are required, thereby eliminating any need for lubricant pipes and seals forward of the alternator. The centrifugal field associated with rotation of the propeller assembly naturally causes grease in the traction unit to migrate to the retaining ring area. Close fitting support discs for the ring gears channel the grease to the outer-roller surfaces, which on rotation, carry the grease to the second-row surfaces. Roller baffles and scrapers direct the grease to the first-row and sun roller surfaces.
Hybrid Traction Drive

Concept. - A key element of the proposed approach is a compact high reduction ratio planetary hybrid (traction/gear) drive (Figs. 6 and 7) that couples the electro-optically controlled high speed electric motor/generator combination to the ball screw-blade link mechanism. The hybrid drive combines the best features of traction and gear components to achieve unusually high power density and efficiency for a high ratio, 210:1 in this case, single stage speed reducer. While single stage differential gear type drives can achieve comparable ratios in one stage, their expected efficiencies in the neighborhood of 80 percent are inferior to the mid-90 percent range for the hybrid drive. High mechanical efficiency means low hysteresis and thus improved control. It also allows a less powerful and therefore smaller, lighter drive motor.

Current work with a larger scale Nasvyt is hybrid transmission are underway at NASA. A recently designed and fabricated $500 \mathrm{hp}$ helicopter main rotor transmission combines the best features of gears with traction rollers ${ }^{9}$ (Fig. 8) and offers potential cost, noise and reliability benefits. This transmission carries 58 percent more power in a test package that is only 22 percent heavier than the production $0 \mathrm{H}-58$ helicopter gear box it models. In a higher ratio version now in testing, a 68 percent increase in power density is realized with a predicted 300 percent or greater improvement in reliability.

The benefits of this transmission, as well as the PCM drive, are attributed to the hybrid's unique geometrical configuration. Gear pinions are affixed to the end of rollers on the outer row. The pinions, in turn, mesh with a collector ring gear (or bull gear) which is normally attached to the low speed output or rotor shaft in this case. In the PCM drive, however, the ring gear is held stationary and the low speed output is taken off the planet carrier. This high torque capacity of the drive per unit weight is due, in part, to the multiple number of parallel load paths on the final mesh. Stepping the rollers in 3 planet roller rows accomplishes the required $210: 1$ in a single unit, thereby eliminating the need for several stages of gearing that successively increase in size, parts count, and weight.

An additional benefit of integrating gears with traction rollers is the ability of the rollers to equalize the load between the gear pinions through traction "creep". Creep is the small difference in velocity generally less than a 0.5 percent between surfaces of the driving and driven rollers due to torque transfer. In the hybrid drive, if one of the pinions is carrying more load than the others then its roller will experience a slightly higher creep rate, allowing the load to equalize. Thus, the traction rollers perform an important secondary function as a torque splitting mechanism. The simultaneous combination of high ratio, high number of redundant load paths and a high degree of load sharing on the final gear mesh is an important feature of the hybrid concept not shared by epicyclic gearing.

Traction drive principles. - The heart of the hybrid drive is the traction drive cluster. Traction drive technology work has been ongoing at NASA 
Lewis Research Center for more than a decade. 10 Research efforts to date can loosely be categorized under one of several areas: (1) modeling the tractive behavior of the lubricant within the contact and its attendant power losses; (2) predicting the useful torque that $c$ an be passed between rollers without surface distress or that amount corresponding to a given fatigue life; (3) determining and improving the durability characteristics of traction drive materials, primarily bearing-grade steels; (4) developing lubricants that product higher traction forces in the contact without sacrificing conventional lubricant qualities; and (5) developing drive arrangements that maximize durability, torque capacity, and ratio capability and minimize size, weight, power loss, and complexity.

Design considerations. - The lubrication principles, operating conditions, and failure mechanisms of traction drive contacts, bearing contacts and those of gears are so similar that the design fundamentals are virtually interchangeable. However, traction drive contacts totally rely on traction to transfer torque between roller pairs separated by a thin lubricant film as illustrated in Fig. 9. A sufficiently large normal load must be imposed on the rollers to transmit the tangential traction force, $T$. The amount of normal load required to transmit a given traction force without destructive gross slip is dictated by the available traction coefficient, $\mu$, which is the ratio of $T$ to $N$. Since the contact fatigue life is inversely related to the third power of normal load, it is extremely desirable to make use of lubricants that produce high values of $\mu$.

In the PCM application, a synthetic traction grease having about 2 to 3 times the $\mu$ of a conventional mineral oil based grease will likely be used. It is important to recognize that this $\mu$ benefit with traction fluids or greases occurs mainly in the low slip region (ascending portion of the traction cure (Fig. 10)) where traction drive contacts operate. In the high sliding region (slide to roll ratios greater than 50 percent) where gear contacts operate, sliding friction coefficient of traction fluids are only slightly greater than conventional mineral oils. This is because in the low slip region, the pressureviscosity characteristics dictate traction while in the high sliding region the thermal viscosity characteristics are important. Thus traction fluids do not seriously compromise gear efficiency.

The traction rollers in the hybrid drive are not in direct contact but are, in fact, separated by a highly compressed, extremely thin lubricant film. Because of the presence of high pressures in the contact, the lubrication process is accompanied by some elastic deformation of the contact surface. Accordingly, this process is referred to as elastohydrodynamic (EHD) lubrication. This phenomenon also occurs for other oil-lubricated rolling-element machine components such as bearings and gears. The importance of the EHD film in traction contacts lies in its ability to reduce and/or eliminate wear while acting as the principal torque transferring medium.

The tribological properties of the lubricant in the contact, particularly its traction characteristics, are fundamental to the design of the traction drives. It is the linear region of the traction curve that is of the greatest interest to designers. The design traction coefficient, which dictates how much normal load is needed to transmit a given traction force, is always chosen to be less than (by, generally, 20 to 30 percent) the peak available traction coefficient to provide a safety margin against slip (Fig. 10). Traction drives are generally equipped with a torque-sensitive loading mechanism that adjusts the normal contact load in proportion to the transmitted torque. Such mechanisms ensure that the contact will always have sufficient load to prevent slip without needlessly overloading the contact under light loads.

Sizing criteria. - The normal expected failure mode of a properly designed traction drive will be rolling-element fatigue. This failure criteria is analogous to pitting or spalling failures in gears and in rolling-element bearings. The risk of wear or scuffing failures of traction drive contacts can be eliminated or greatly minimized through the use of proper materials and also proper lubricating and cooling design practices, such as those that have been successfully applied in bearing and gear design. In view of this similarity in the failure mechanism, it is expected that the fatigue life theory of Lundberg and Palmgren, 11 the accepted method of establishing load capacity ratings for rolling-element bearings by bearing manufacturers, can be adapted to predicting traction drive service life. In Ref. 12, the basic life equations for traction drives were developed from LundbergPalmgren theory and applied to a toroidal type traction drive. Life adjustment factors due to advances in materials, lubricants and design technology were also considered. In Ref. 13, this life analysis was applied to Nasvytis traction drive geometry, which is employed in the hybrid drive configuration.

In Ref. 14 a simplified version of the Lundberg-Palmgren fatigue life theory was developed for traction drive contacts, and in Ref. 15 this method was used to show the effects of torque, size, speed, contact shape, traction coefficient and number of multiple, parallel contacts on predicted drive life. These investigations show that multiple, load-sharing contacts significantly benefit torque capacity and drive life. Also, torque capacity and drive life are proportioned to size to the 2.8 and 8.4 power, respectively as shown in Fig. 11. Because of this high sensitivity to component size, the traction drive subassembly in the unit can be readily scaled to meet the $15000 \mathrm{hr}$ mean time between unscheduled removal requirement for the ATP design. In view of the fact that the PCM will spend most if its time in a low speed "hunting" mode, the stress cycling rate will be low. This coupled with the use of a high traction grease and premium double-vacuum-processed bearing steels, such as VIM-VAR AISI M50 will minimize the potential for traction drive contact durability problems.

0ther test drives. - A NASA program was initiated in the early 70's which used the traction drive, pictured in Fig. 12 , as a test bed fo investigate advanced traction drive technology. 10 This particular drive configuration was developed by A. L. Nasvytis in the late 60's. 16 The first of several drives tested was a $373 \mathrm{~kW}(500 \mathrm{hp})$ torpedo drive of three-planet row construction with a reduction ratio of 48.2 and an input speed of 53000 $\mathrm{rpm}$. The outside diameter of the drive itself was $43 \mathrm{~cm}$ (17 in.) and it weighed just $930 \mathrm{~N}(210 \mathrm{lb})$, 
including its lightweight magnesium housing. It demonstrated a mechanical efficiency above 95 percent. To investigate uitrahigh-speed operation, Hasvyt is tested a $3.7 \mathrm{~kW}(5 \mathrm{hp})$, three-row, 120:1 ratio speed increaser. The drive was preloaded and operated without torque at $480000 \mathrm{rpm}$ for 15 min and ran for 43 consecutive hr at $360000 \mathrm{rpm}$ without lubrication but with air cooling.

Based on the inherent qualities of the Nasuytis drive, a NASA program was initiated 8 to parametrically test two versions of the drive. These drives of nominally 14:1 ratio were tested at speeds to $73000 \mathrm{rpm}$ and power levels to $180 \mathrm{~kW}$ $(240 \mathrm{hp})$. Parametric tests were also conducted with the Nasvytis drive retrofitted to an automotive gas-turbine engine. The drives exhibited good performance, with a nominal peak efficiency of 94 to 96 percent and a maximum speed loss due to creep of approximately 3.5 percent. The drive package size of approximately $25 \mathrm{~cm}$ (9.81 in.) in diameter by $11 \mathrm{~cm}$ (4.33 in.) in width (excluding shafting) and total weight of about $26 \mathrm{~kg}(58 \mathrm{lb})$ makes the Nasvytrac drive, with a rated mean life of about $12000 \mathrm{hr}$ at $75 \mathrm{~kW}(100 \mathrm{hp})$ and 75000 rpm, size competitiye with the best commercial gear drive systems. 15 In addition, a 70000 rpm, 10.8-to-1 reduction ratio Nasvyt is drive weighing just $4 \mathrm{~kg}$ (9 $\mathrm{lb}$ ) was designed, built and tested for a long-life, rocket-engine pump drive system to drive low-speed liquid-oxygen and liquidhydrogen boost pumps. 17

\section{Other Considerations}

The PCM concept presented offers considerable promise for single rotation, advanced turboprop propulsion systems. Also under evaluation are counter rotating propeller systems for advanced turboprop aircraft which offer some additional advantages in noise and fuel burn. Although commercial Soviet aircraft employing counter rotating propellers have been produced, no similar propulsion system has yet been commercially certified in the Western World. While the proposed PCM concept appears, in principle, to be adaptable to counter rotation drive systems, the integration of this mechanism with a radically different counter rotating output main reduction gearbox needs further study.

Application of a fiber optically controlled, electronically commutated electric motor for pitch control is a significant departure from prior approaches. Verification testing is obviously desirable. Failure modes and reliability characteristics need further definition. While the proposed system appears to offer exceptional positioning accuracy, this still must be borne out from system tests under appropriate transient loading. Finally, the durability characteristic of the hybrid drive appears to analytically lend itself to meeting the high reliability requirements of a PCM, this also needs experimental substantiation.

\section{Summary and Conclusions}

This paper discusses the pitch change requirements of advanced turboprop aircraft in comparison with those of conventional and early applications. Because of the very large blade twisting moment torque of nearly $500000 \mathrm{in.} \mathrm{Ib} \mathrm{(comparable} \mathrm{to} \mathrm{the}$ main reduction gearbox output torque) and the precise blade positional accuracy requirements associated with these systems, it is advantageous to examine new approaches to synthesize an optimum system.

An innovative mechanism capable of meeting or exceeding the blade pitch requirements for advanced turboprop aircraft has been described. The mechanism incorporates a high power density, electronically commutated alternator/motor drive module for accurately positioning the blades. This alternator driven by a power takeoff shaft from the main reduction gearbox thus eliminates the need for electrical slip rings or hydraulic transfer seals. Control signal information, provided by a full authority digital controller in the cockpit passes across the rotating spinner interface to the rotating electronic controller through an optical coupling. Precise blade position is achieved through a high reduction drive system consisting of a hybrid drive and ball screw. The high reduction ratio planetary hybrid drive which offers low torque ripple with high torsional stiffness fits compactly in the front of the propeller hub and is a key element in this design. The hybrid drive accepts the $20000 \mathrm{rpm}$ motor speed and reduces it by a factor or 210 to drive the ball screw. The nut on the ball screw positions the blade through a simple link. Emergency feather and pitch lock features are included. These features will be operable with any perceived failure of normal electrical control system elements or of the alternator/motor.

Commercial acceptance of an advanced turboprop aircraft is dependent on many factors, one of which is the long term integrity and performance of the PCM. The proposed concept appears to successfully meet all of the currently defined requirements for an advanced $P C M$.

\section{Acknowledgement}

Portions of the work described herein was performed by the General Electric Company under NASA Contract NAS3-23044 directed by Mr. Gerald kraft. The authors wish to acknowledge the technical efforts and comments contributed by Mr. Millard Mayo of the Hamilton Standard Corporation.

\section{References}

1. Bass, R. M., "An Historical Review of Propeller Developments," Aeronautical Journal, Aug./Sept. 1983, pp. 255-267.

2. Aircraft Systems Dept., Hamilton Standard Co., "Quiet Clean Short-Haul Experimental Engine (QCSEE): Hamilton Standard Cam/ Harmonic Drive Variable Pitch Fan Actuation System Detail Design Report," NASA CR-134852.

3. Advanced Engineering and Technology Programs Dept., General Electric Co.: "Quiet Clean Short-Haul Experimental Engine (QCSEE): Ball Spline Pitch Change Mechanism Design Report," NASA CR-134873.

4. Gatzen, B. S., Adamson, W. M., Prop-Fan Technical Progress Leading to Technology Readings, Technical Paper, AIAA-81-0810-CP. 
5. Toraason, C. M., Broman, C. L., Advanced Gearboxes for a Modern Single Rotation Turboprop Engine, Report presented at the AIAA/SAE/ASME 20th Joint Propulsion Conference, June, 1984.

6. Hayes, W. C., "Special Report Fiber Optics: The Future is Now," Electric World, Feb. 1984.

7. Rohn, D. A., Loewenthal, S. H., "An Analysis of Traction Drive Torsional Stiffness," To be presented at the ASME Fourth International Power Transmission and Gearing Conference, October, 1984

8. Loewenthal, S. H., Anderson, N. E., and Rohn, D. A., "Evaluation of a High Performance Fixed-Ratio Traction Drive," Journal of Mechanical Design, Vo1. 103, April 1983.

9. Nasvytis, A. L., and White, G., "Hybrid Geared Traction Transmission," in "Advanced Power Transmission Technology," NASA CP-2210,

Fischer, G. K., ed., 1982, pp. 161-172.

10. Loewenthal, S. H., Anderson, N. E., and Rohn, D. A., "Advances in Traction Orive Technology," NASA TM-83397, September, 1983.
11. Lundberg, G., and Palmgren, A., "Dynamic Capacity of Rolling Bearings," Ingenioersvetenskapsak ademian, Hand linger, Ho. 196, 1947.

12. Coy, J. J., Loewenthal, S. H., and Zaretsky, E. V., "Fatigue Life Analysis for Traction Orives with Application to a Toroidal Type Geometry," NASA TN D-8362, 1976.

13. Coy, J. J., Rohn,, D. A., and Loewenthal, S. H., "Life Analysis of a Multiroller/Planetary Traction Drive," NASA TP-1710, 1981.

14. Rohn, D. A., Loewenthal, S. H., and Coy, J. J., "Simplified Fatigue Life Analys is for Traction Drive Contacts," Journal of Mechanical Design, Vol. 103, No. 2, April 1981 , pp. 430-439.

15. Rohn, D. A., Loewenthal, S. H., and Coy, J. J., "Sizing Criteria for Traction Drives," in "Advanced Power Transmission Technology," NASA CP-2210, Fisher, G. K., ed., 1982, pp. 229-316.

16. Nasvytis, A. L., "Multiroller Planetary Friction Drives," SAE Paper No. 660763, October 1966.

17. Meyer, S., and Conne11y, R. E., "Traction Drive for Cryogenic Boost Pump," NASA TM-81704, 1981 . 
TABLE I. - PROPFAN PCM DATA

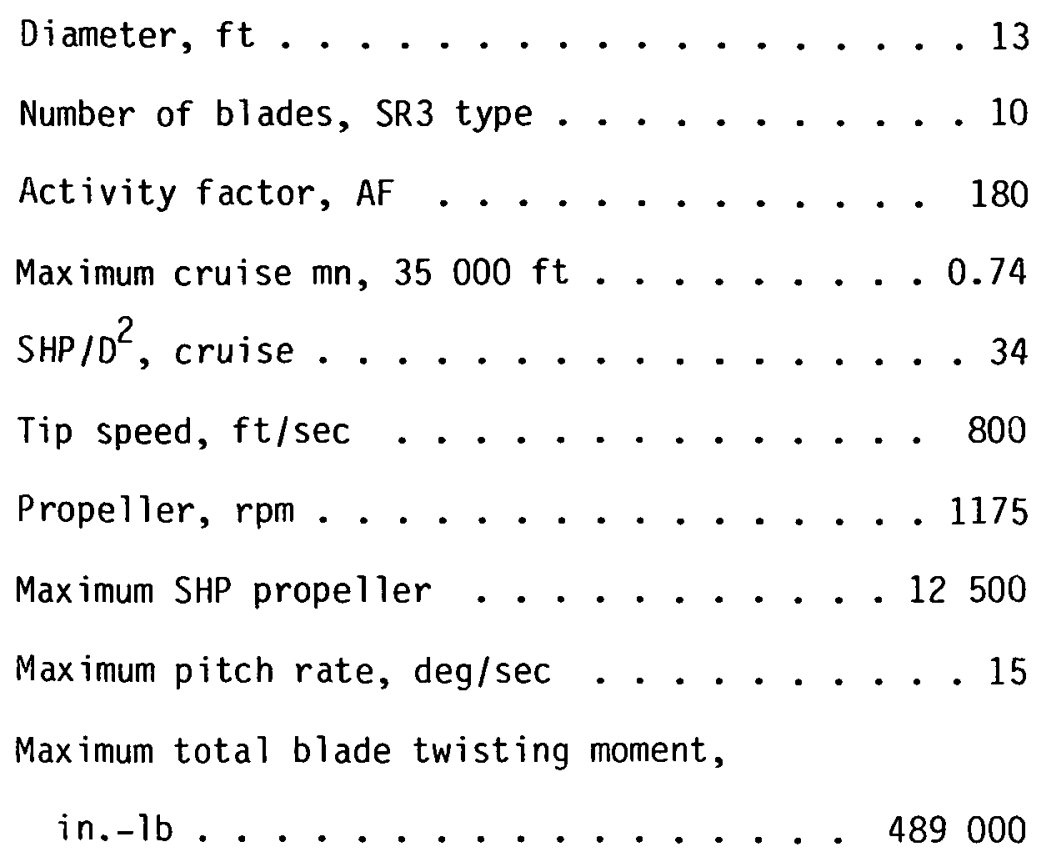




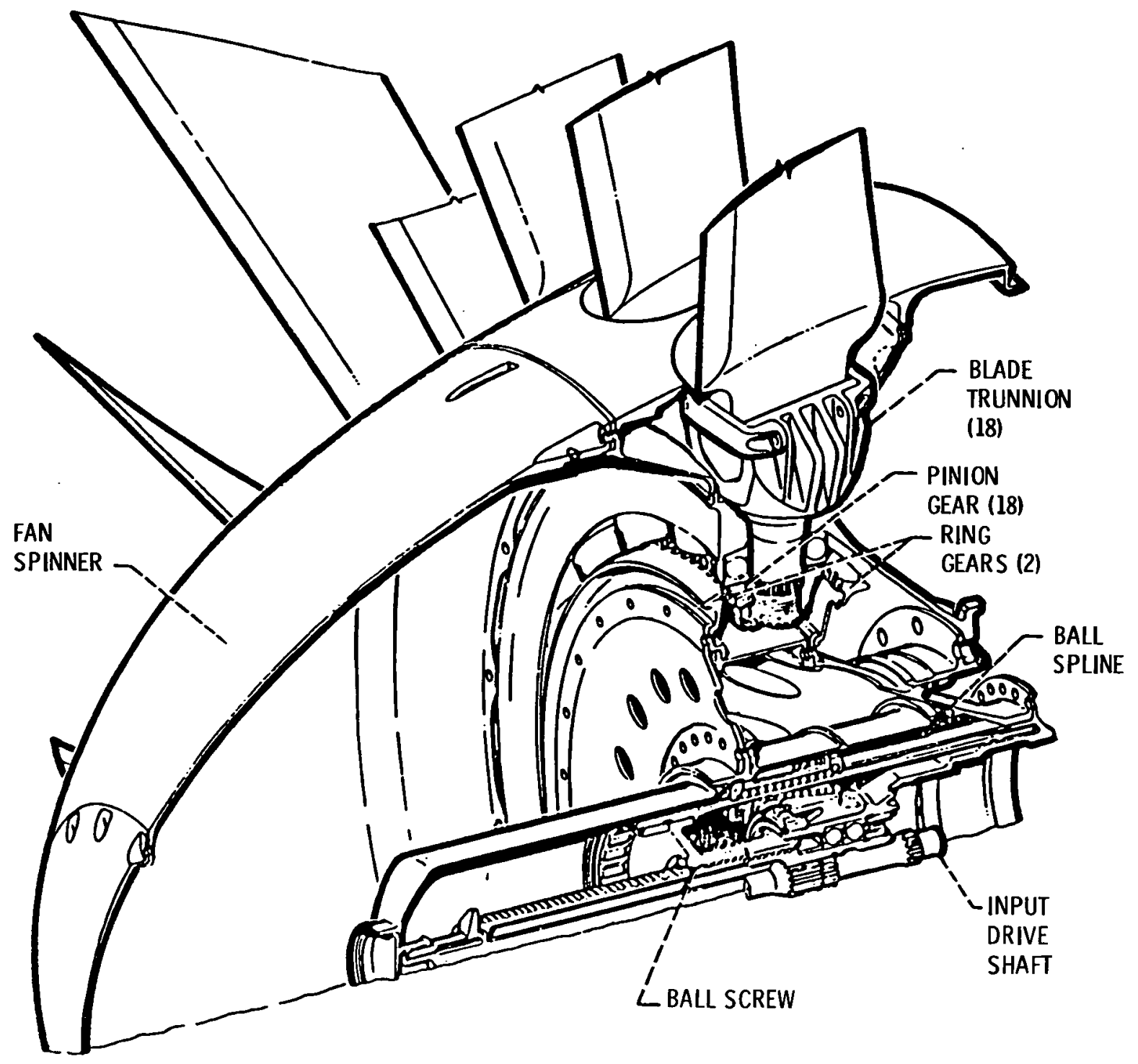

Figure 1. - GE ball spline actuator system. 


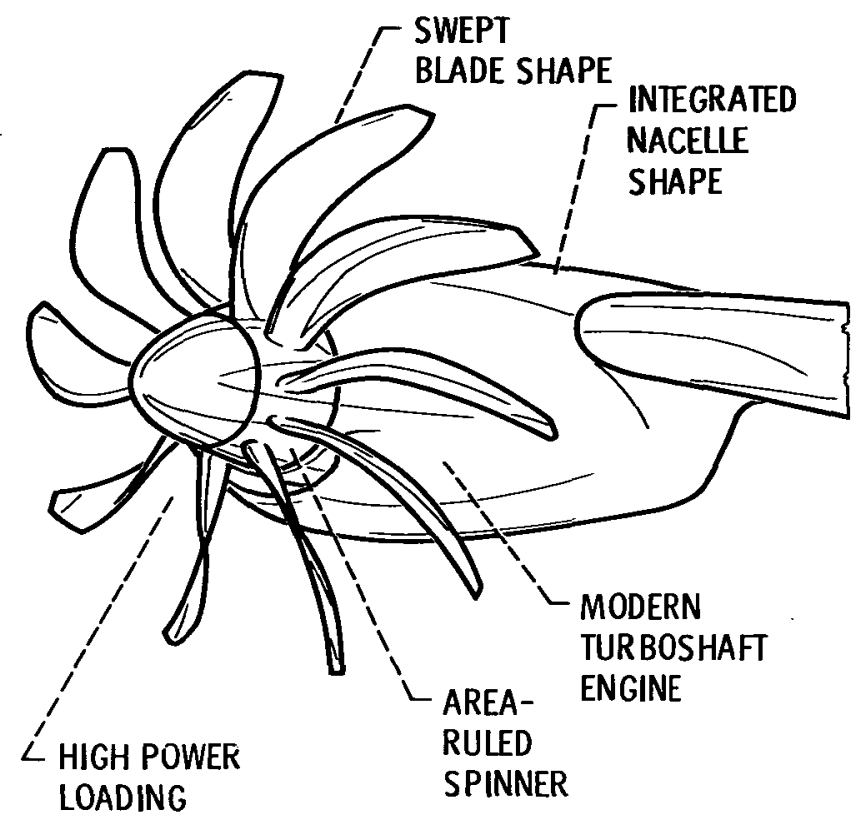

Figure 2. - Ten bladed variable pitch propfan (ref. 4).

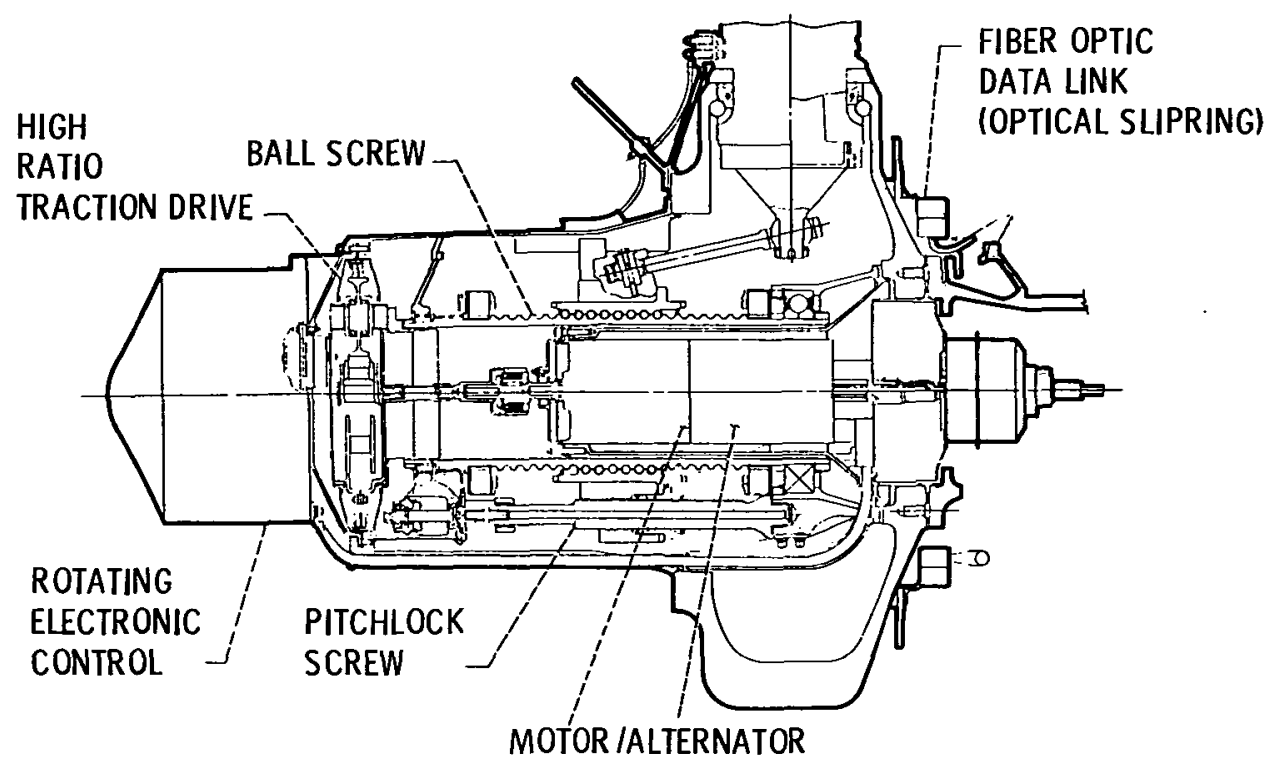

Figure 3. - Advanced technology pitch control system. 


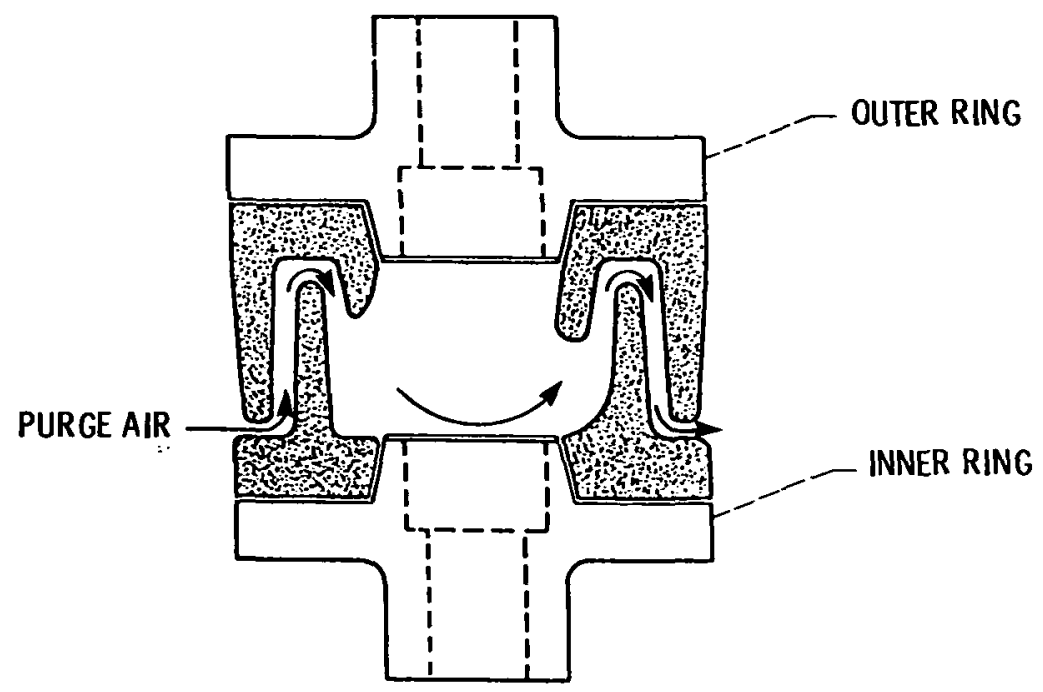

Figure 4. - Cross section of one possible configuration of an optical slip ring.

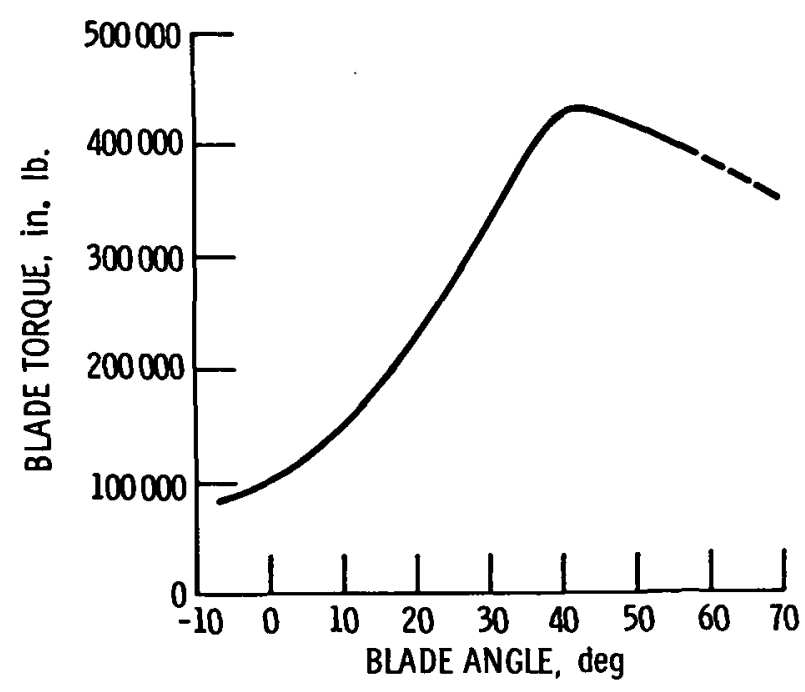

Figure 5. - Blade torque versus blade angle. 


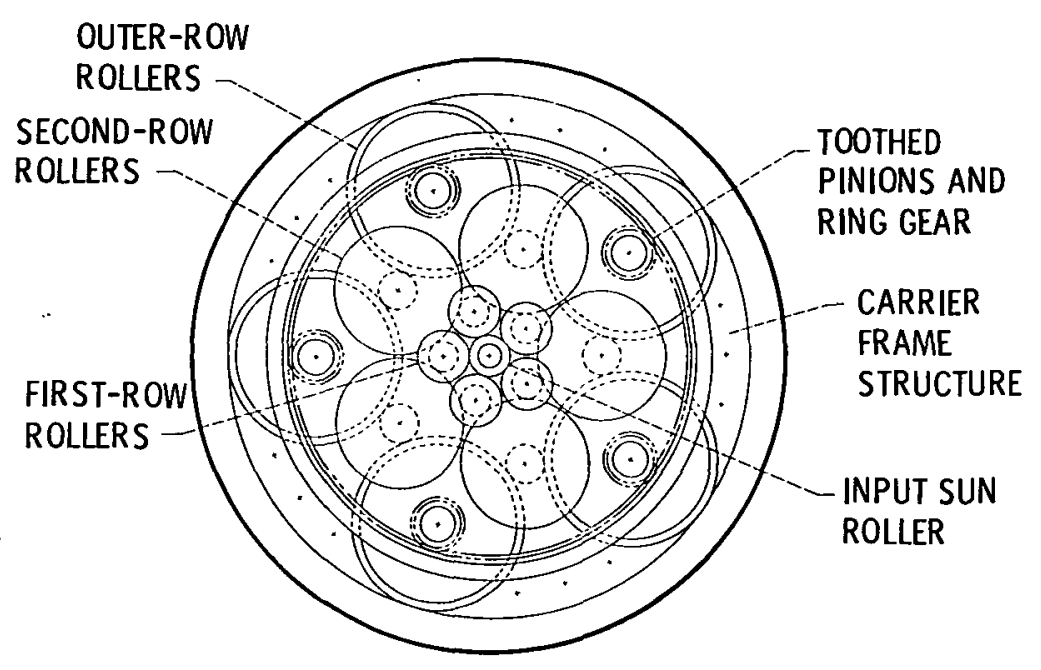

Figure 6. - Traction drive arrangement for 210:1 ratio. 


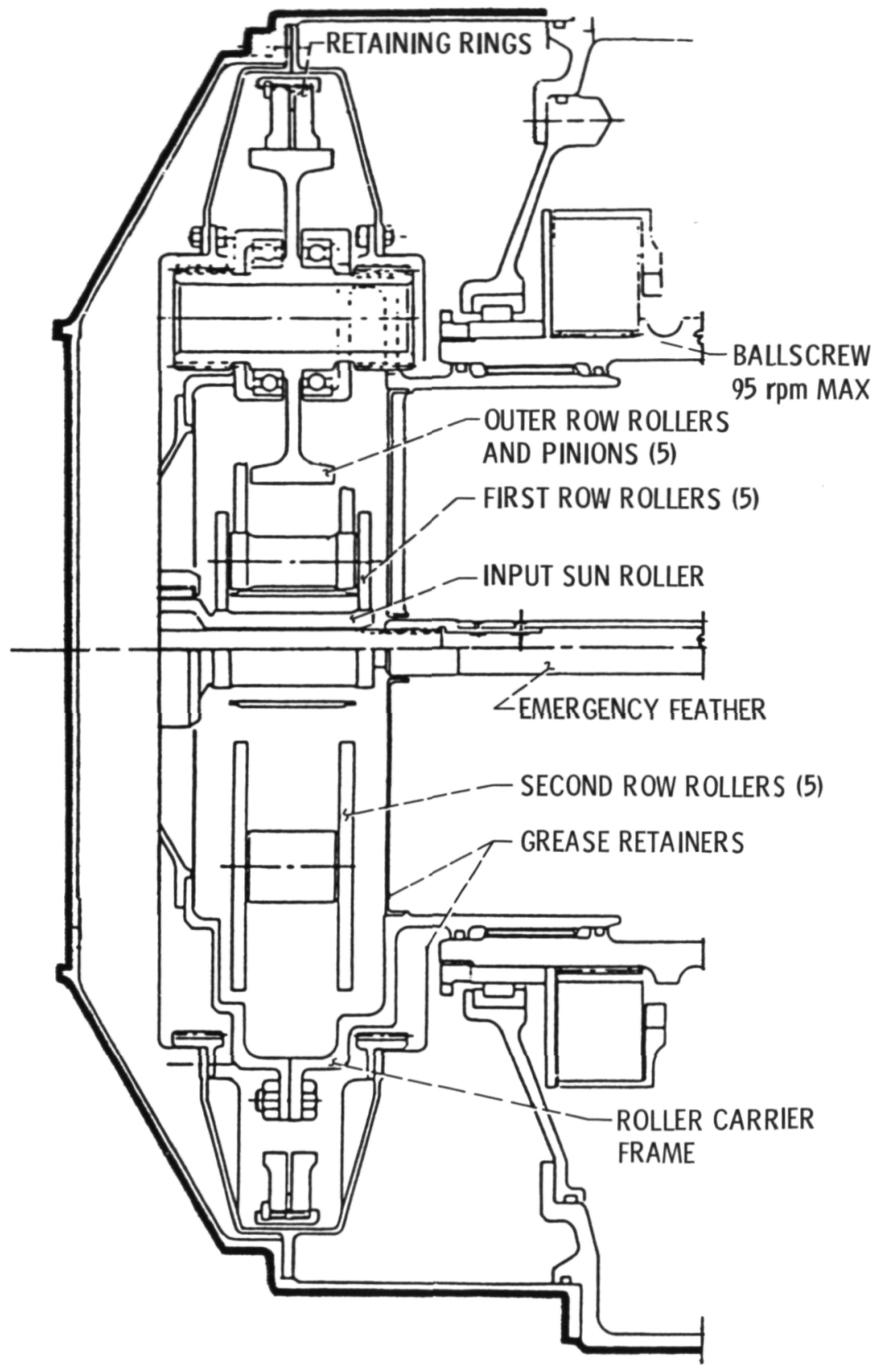

Figure 7, - Traction drive arrangement for 210:1 ratio. 


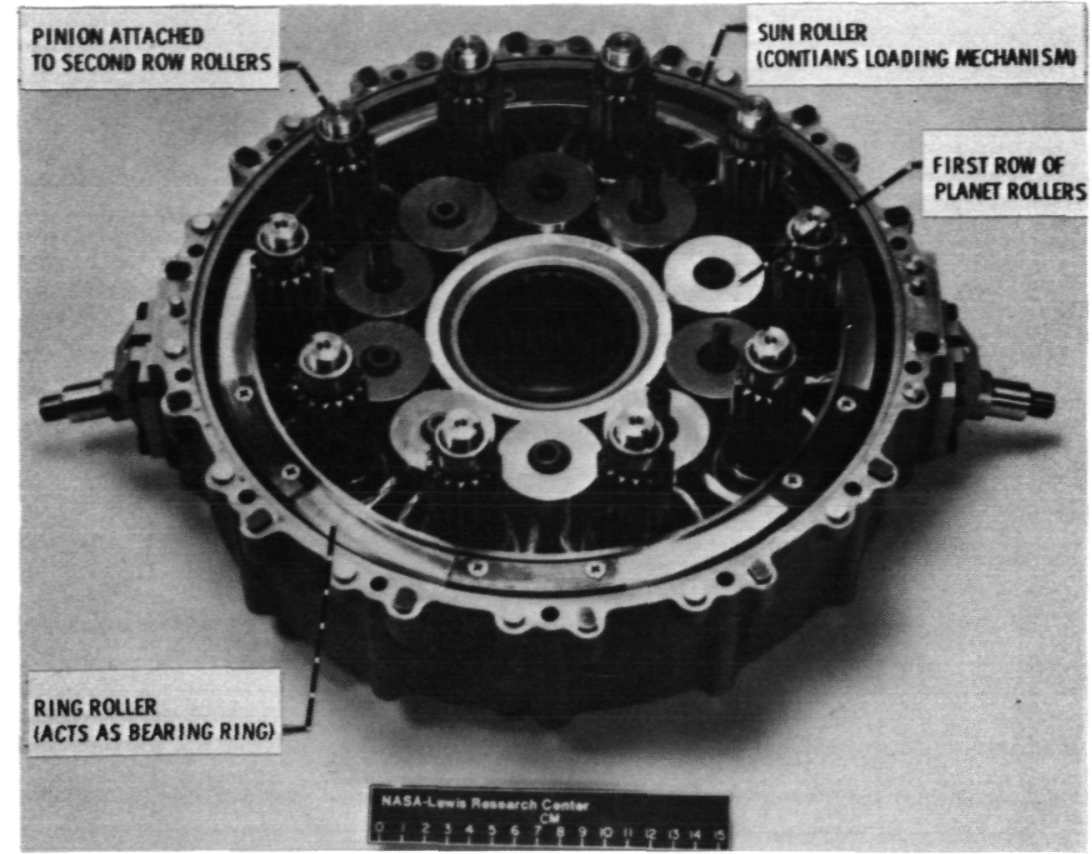

Figure 8. - 500 HP hybrid helicopter transmission.
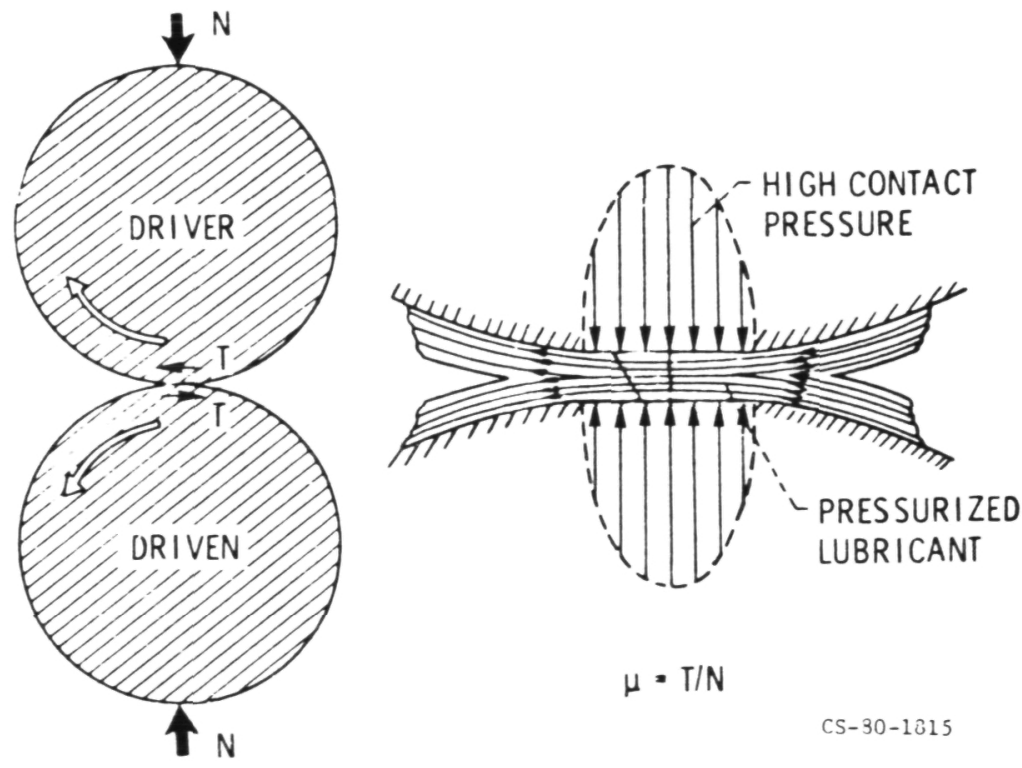

$\mu=T / N$

CS-30-1815

Figure 9. - Power transfer through traction. 


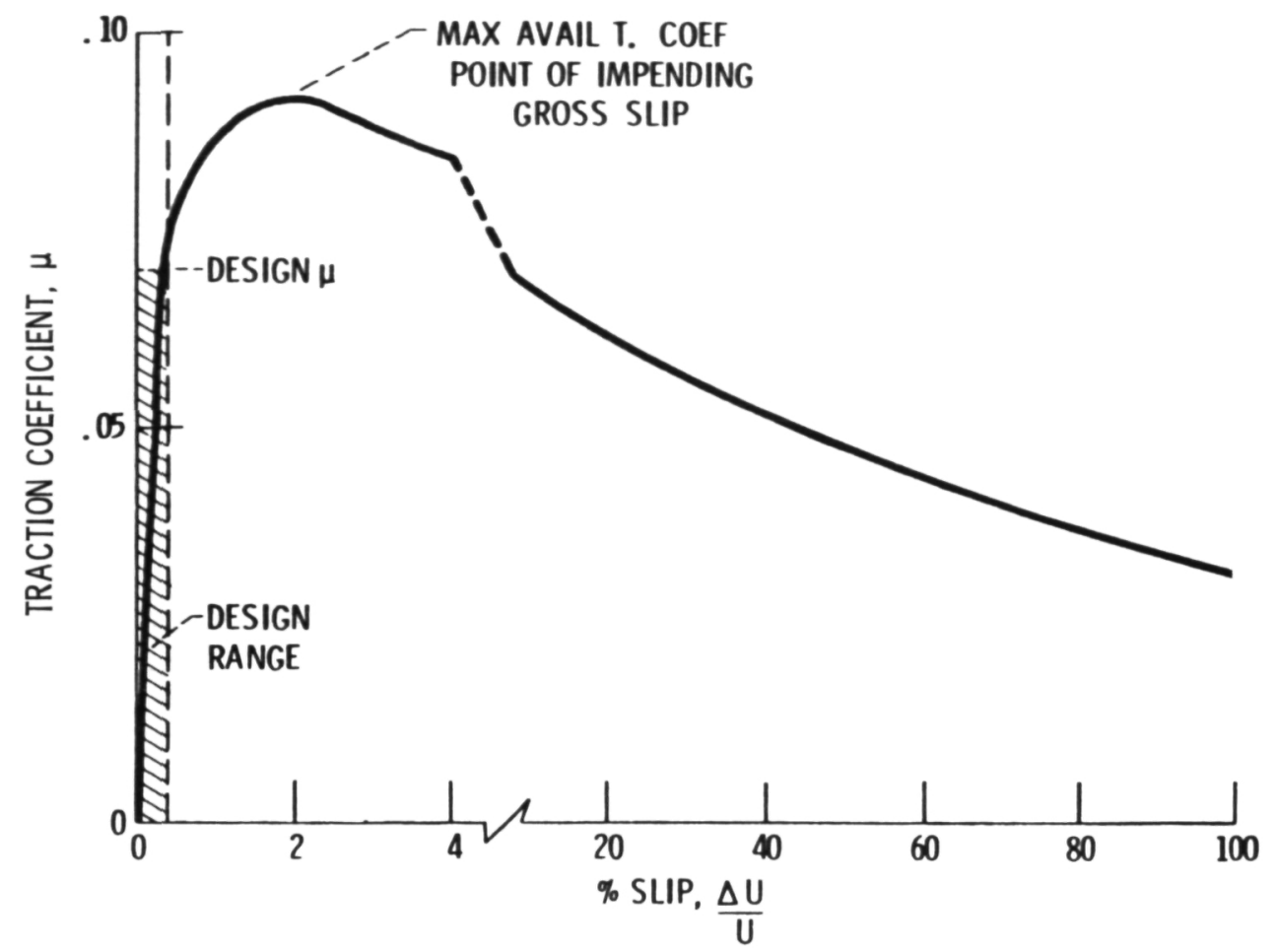

Figure 10. - Typical traction curve showing design range for traction drives.

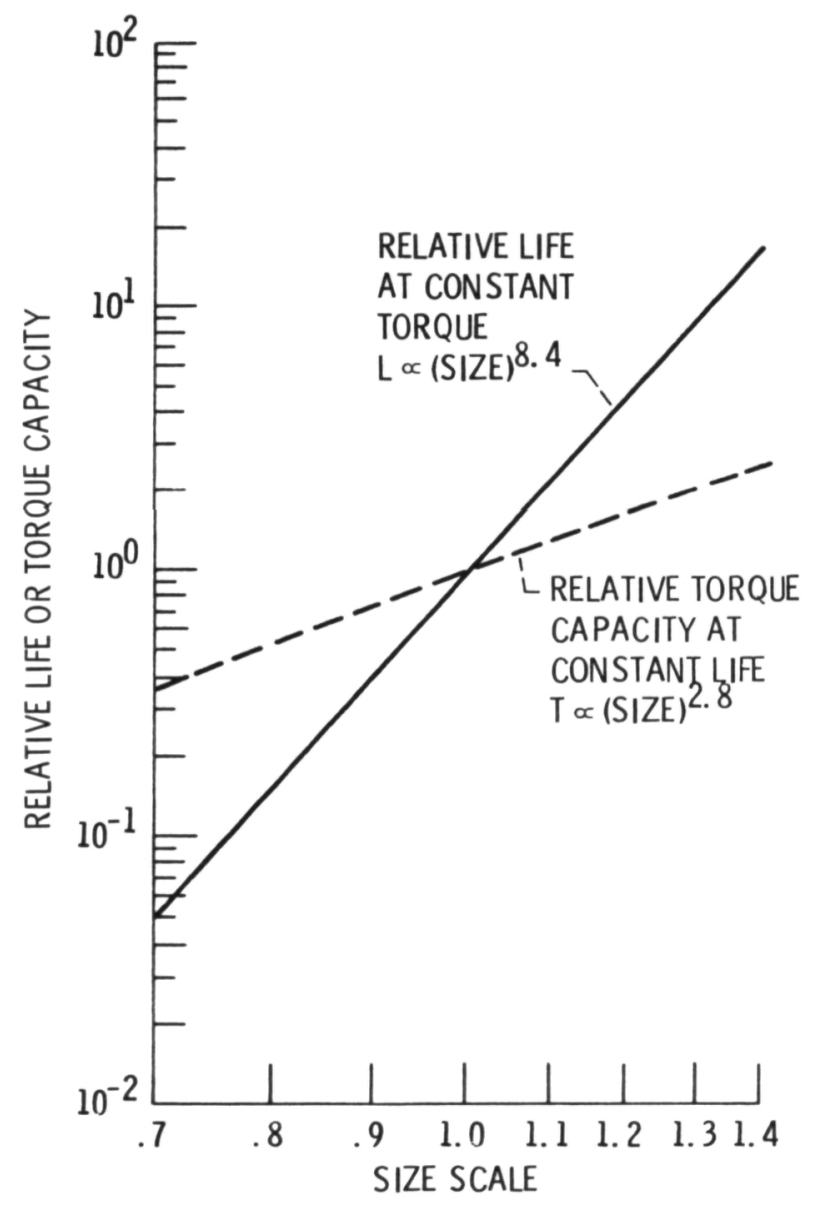

Figure 1l. - Relative life at constant torque and relative torque capacity at constant life versus relative size (ref. 15). 


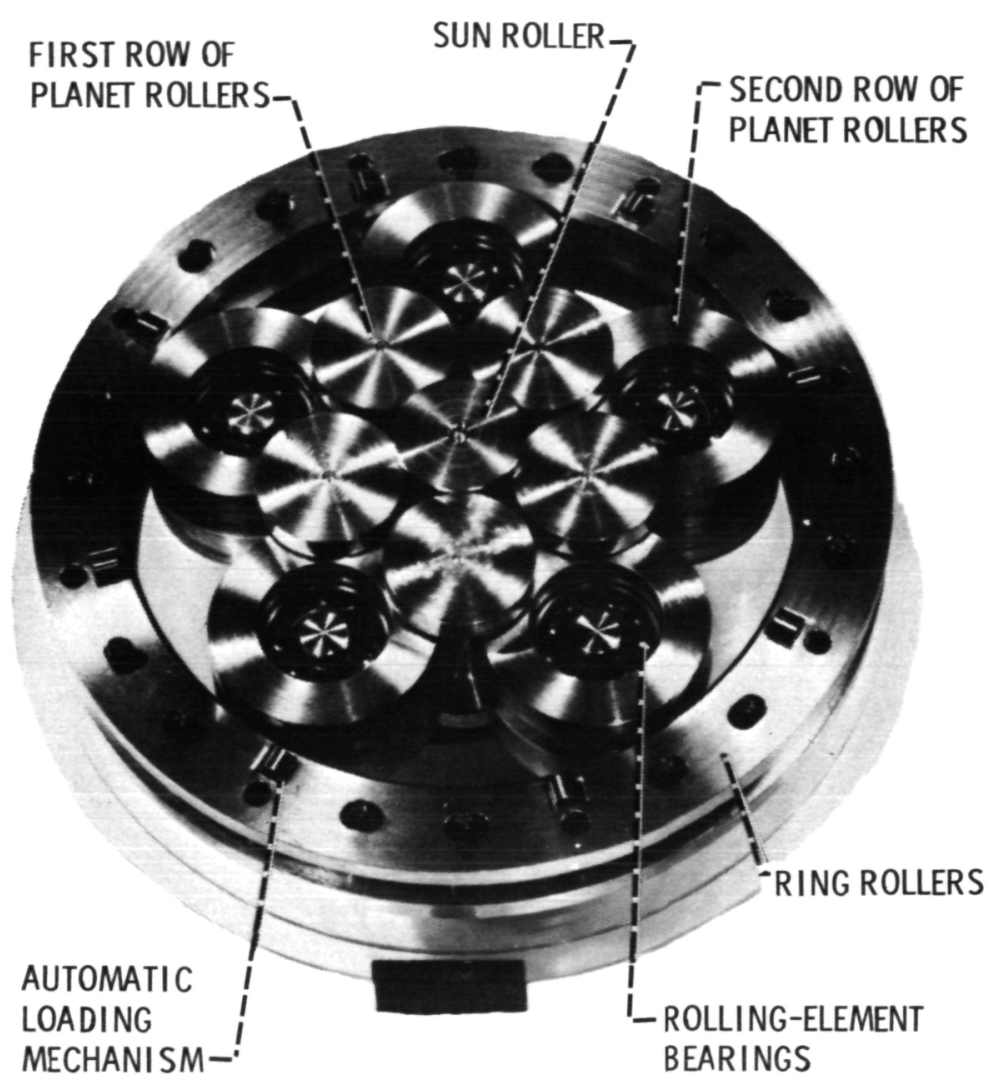

Figure 12. - Geometry of the Nasvytis traction (Nasvytrac) test drive. 


\begin{tabular}{|c|c|c|c|c|}
\hline $\begin{array}{l}\text { 1. Report No. NASA TM-83709 } \\
\text { AIAA- } 84-1383\end{array}$ & \multicolumn{2}{|c|}{ 2. Government Accession No. } & \multicolumn{2}{|c|}{ 3. Recipient's Catalog No. } \\
\hline \multirow{2}{*}{\multicolumn{3}{|c|}{$\begin{array}{l}\text { 4. Title and Subtitle } \\
\text { An Advanced Pitch Change Mechanism Incorporating a } \\
\text { Hybrid Traction Drive }\end{array}$}} & \multicolumn{2}{|l|}{\begin{tabular}{|l|} 
5. Report Date \\
$505-40-42$
\end{tabular}} \\
\hline & & & \multicolumn{2}{|c|}{$\begin{array}{l}\text { 6. Pertorming Organization Code } \\
\text { E-2137 }\end{array}$} \\
\hline \multirow{2}{*}{\multicolumn{3}{|c|}{$\begin{array}{l}\text { 7. Author(s) } \\
\text { Bruce M. Steinetz, Donald F. Sargisson, Graham White, } \\
\text { and Stuart H. Loewenthal }\end{array}$}} & \multicolumn{2}{|c|}{ 8. Performing Organization Report No. } \\
\hline & & & \multicolumn{2}{|l|}{ 10. Work Unit No. } \\
\hline \multirow{2}{*}{\multicolumn{3}{|c|}{$\begin{array}{l}\text { 9. Performing Organization Name and Address } \\
\text { National Aeronautics and Space Administration } \\
\text { Lewis Research Center } \\
\text { Cleveland, Ohio } 44135\end{array}$}} & \multicolumn{2}{|c|}{\begin{tabular}{|l|} 
11. Contract or Grant No. \\
\end{tabular}} \\
\hline & & & \multirow{2}{*}{\multicolumn{2}{|c|}{$\begin{array}{l}\text { 13. Type of Report and Period Covered } \\
\text { Techni cal } 1 \text { Memorandum }\end{array}$}} \\
\hline \multicolumn{3}{|c|}{ 12. Sponsoring Agency Name and Address } & & \\
\hline \multicolumn{3}{|c|}{$\begin{array}{l}\text { National Aeronautics and Space Administration } \\
\text { Washington, D.C. } 20546\end{array}$} & \multicolumn{2}{|c|}{ 14. Sponsoring Agency Code } \\
\hline \multicolumn{5}{|c|}{$\begin{array}{l}\text { 15. Supplementary Notes Bruce M. Steinetz, Lewis Research Center; Donald F. Sargisson, Gen- } \\
\text { eral Electric Company, Evendale, Ohio 45215; Graham White, Transmission Research } \\
\text { Incorporated, Cleveland, Ohio 44106; Stuart H. Loewenthal, Lewis Research Center. } \\
\text { Prepared for the Twentieth Joint Propulsion Conference cosponsored by the AIAA, } \\
\text { SAE, and ASME, Cincinnati, Ohio, June 11-13, } 1984 \text {. }\end{array}$} \\
\hline \multicolumn{5}{|c|}{$\begin{array}{l}\text { 16. Abstract } \\
\text { A design of a propeller pitch control mechanism is described that meets the } \\
\text { demanding requirements of a high-power, advanced turboprop. In this application, } \\
\text { blade twisting moment torque can be comparable to that of the main reduction } \\
\text { gearbox output: precise pitch control, reliability and compactness are all at a } \\
\text { premium. A key element in the design is a compact, high-ratio hybrid traction } \\
\text { drive which offers low torque ripple and high torsional stiffness. The traction } \\
\text { drive couples a high speed electric motor/alternator unit to a ball screw that } \\
\text { actuates the blade control links. The technical merits of this arrangement } \\
\text { and the performance characteristics of the traction drive are discussed. Compari- } \\
\text { sons are made to the more conventional pitch control mechanisms. }\end{array}$} \\
\hline \multicolumn{5}{|l|}{ 17. Koy Worde (Sugpested by Author(s)) } \\
\hline \multicolumn{2}{|c|}{$\begin{array}{l}\text { Advanced turboprop } \\
\text { Hybrid traction drive } \\
\text { Propeller pitch change mechanism }\end{array}$} & \multicolumn{3}{|c|}{$\begin{array}{l}\text { Unclassified - unlimited } \\
\text { STAR Category } 01\end{array}$} \\
\hline $\begin{array}{l}\text { 19. Security Cleself. (of this report) } \\
\text { Uncl ass i fied }\end{array}$ & 0. Security C & sified & 21. No. of peapes & 22. Price" \\
\hline
\end{tabular}

-For sale by the National Technical Information Service, Springfield, Virginia 22161 
National Aeronautics and Space Administration

Washington, D.C.

20546

Official Business

Penalty for Private Use, $\mathbf{\$ 3 0 0}$

\section{SPECIAL FOUATH CLASS MAIC.} Dook

Portace and Fees Pain National Aeroneutici und Space Administration NASA-451

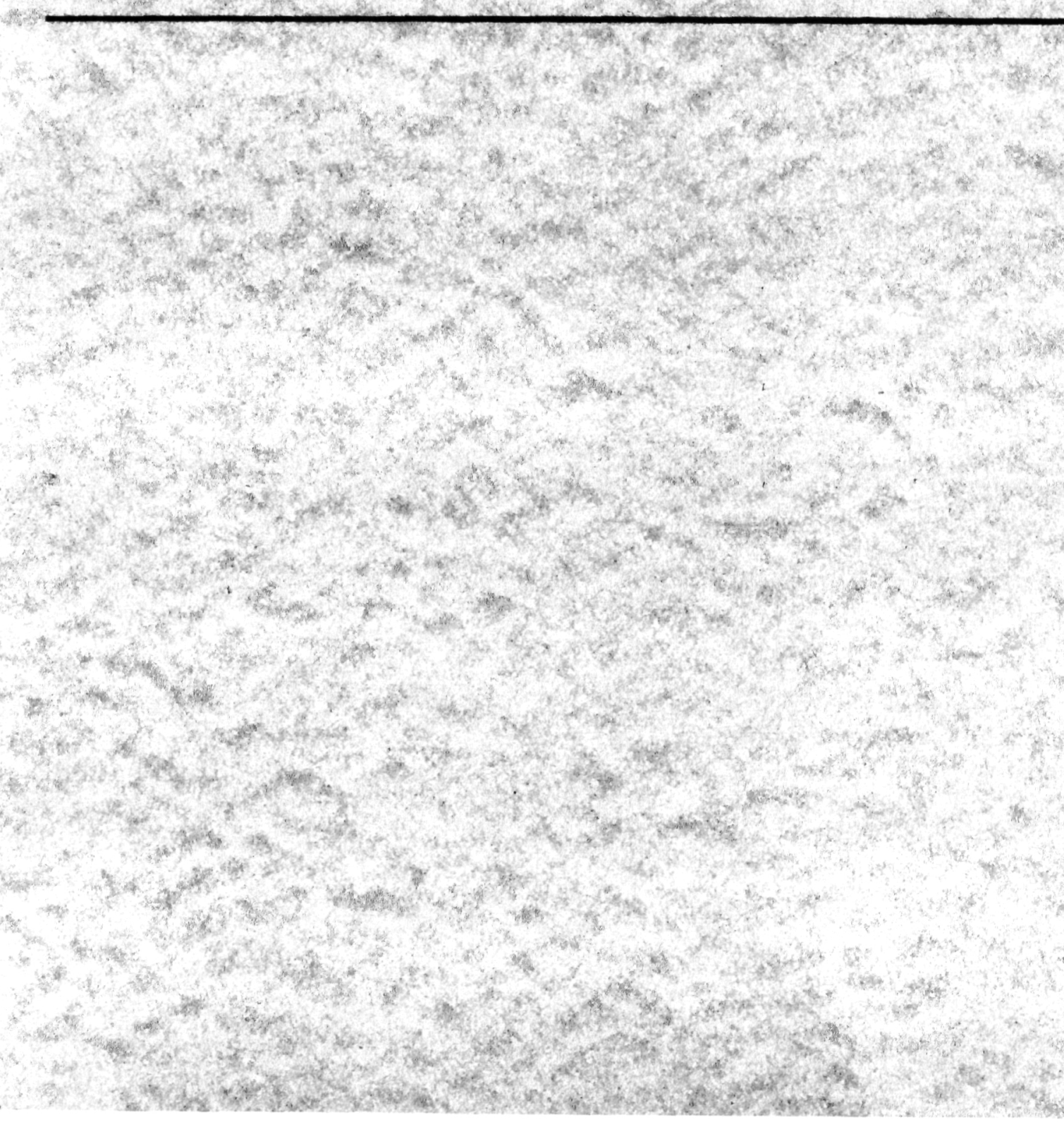

